Boise State University

ScholarWorks

$1-1-2012$

\title{
Near-Surface Imaging of a Hydrogeothermal System at Mount Princeton, Colorado Using 3D Seismic, Self-Potential, and DC Resistivity Data
}

\author{
Andrew P. Lamb \\ Boise State University \\ Lee M. Liberty \\ Boise State University \\ Kasper van Wijk \\ Boise State University \\ André Revil \\ Colorado School of Mines \\ Chuck Diggins \\ Sigma3
}




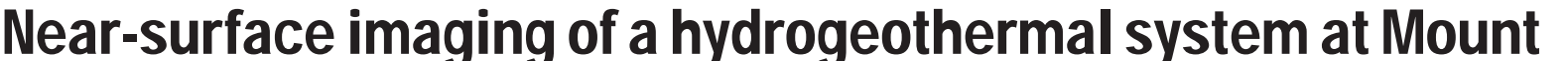

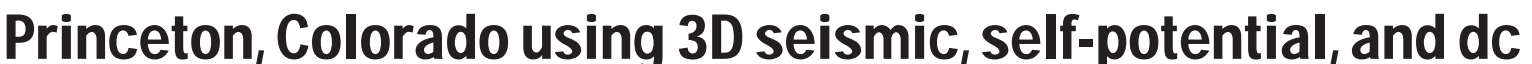

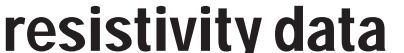

\author{
Andrew P. Lamb, Lee M. Liberty, and Kasper van WiJk, Boise State University \\ Andre REVIL, Colorado School of Mines \\ CHuCK DIGGINs, Sigma3
}

$\mathrm{T}^{\mathrm{k}}$ he Upper Arkansas Valley in the Rocky Mountains of central Colorado is the northernmost extensional basin of the Rio Grande Rift (Figure 1). The valley is a half graben bordered to the east and west by the Mosquito and Sawatch ranges, respectively. The Sawatch Range is home to the Collegiate Peaks, which include some of the highest summits in the Rocky Mountains. Some Collegiate Peaks over $4250 \mathrm{~m}(14,000 \mathrm{ft})$ from north to south include Mount Harvard, Mount Yale, Mount Princeton, and Mount Antero. The Sawatch range-front normal fault strikes northnorthwest along the eastern margin of the Collegiate Peaks and is characterized by a right-lateral offset between the Mount Princeton batholith and Mount Antero. This offset in basin-bounding faults is accommodated by a northeastsouthwest dextral strike-slip transfer fault (Richards et al., 2010) and coincides with an area of hydrogeothermal activity and Mount Princeton Hot Springs. This transfer fault is here termed the Chalk Creek fault due to it's alignment with the Chalk Creek valley. A $250-\mathrm{m}$ high erosional scarp, called the Chalk Cliffs, lies along the northern boundary of this valley. The cliffs are geothermally altered quartz monzonite and not chalk. These cliffs coincide with the Chalk Creek fault, whose intersection with the Sawatch range-front normal fault results in a primary pathway for upwelling geothermal waters.

Faults can form rapid transport pathways for deep heated geothermal fluids (Fairley and Hinds, 2004) and surface expression of these fluids in the form of hot springs often appears at intersecting fault systems. The Mount Princeton Hot Springs, near the intersection of the Sawatch range-front normal fault and Chalk Creek fault (Figure 1), is an example of a geothermal system controlled by intersecting faults. Mapping these faults and associated fractures will help to improve our understanding of the geothermal system and to determine its potential as an economic resource.

We use 3D seismic, self-potential, and dc electrical resistivity data to investigate an area of upwelling hot water in a site that is here termed Long's Field after the surname of the property's owner. The dc electrical resistivity and self-potential data previously identified an area of upwelling hot water that has been interpreted to be the consequence of small tensile fractures $500 \mathrm{~m}$ south of the intersection between the Sawatch and Chalk Creek faults (Richards et al.). These tensile fractures, likely related to the local dilatant stress field, have been shown to radiate from fault tips at intersecting faults in regions with similar structural geology (Roberts, 1996). Our objective is to identify and characterize these fractures through the use of various near-surface geophysical methods. We use the results of our data processing to further enhance the interpretations of Richards et al. by jointly interpreting seismic results with dc resistivity and selfpotential data.

\section{The site}

Long's Field is Quaternary glacial till and alluvial sediments overlying geothermally altered Tertiary quartz monzonite. The field is at a lateral transition between hot and cold groundwater as observed in water wells in the area (Figure 2). Hot water wells are aligned east-west with the most northerly and southerly wells defining a 200-m corridor with geothermal activity. Self-potential and dc resistivity surveys helped explain the possible reasons for the pattern of hot water wells in the valley and identified specific areas of upwelling hot water that were interpreted to coincide with fault A (Figure 2). To further investigate these upwelling hot water events, we designed a $235 \times 220$-m high-resolution multicomponent 3D seismic survey to coincide with the largest upwelling event at the eastern portions of this corridor (Figures 2 and 3).

\section{Data acquisition and processing}

The 3D survey design is shown in Figure 3 and the acquisition parameters are summarized in Table 1 . With a 192-channel recording system and a 576-receiver spread, the active receiver spread was rolled over and all shot stations revisited three times.

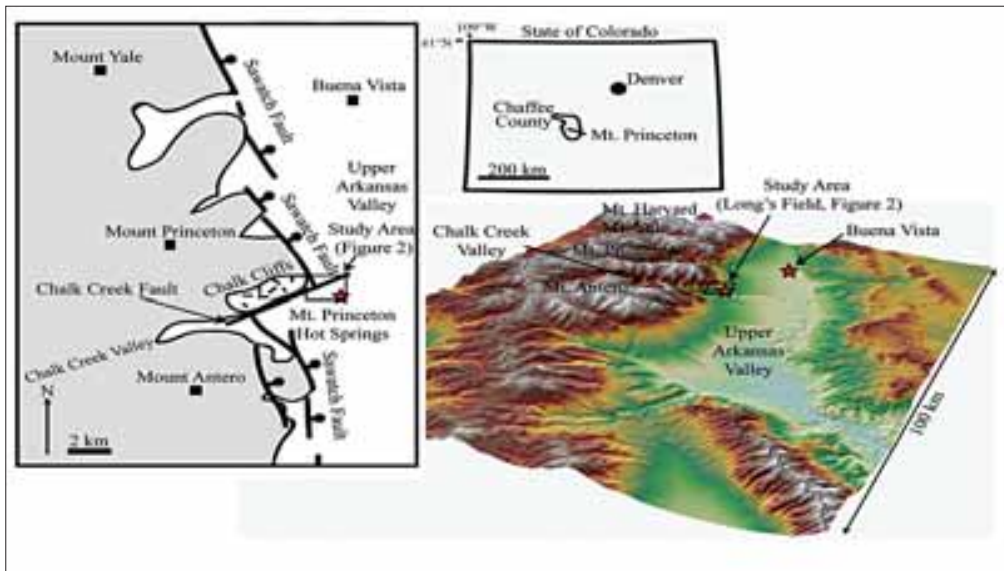

Figure 1. Study area in the Upper Arkansas Valley of central Colorado and the specific field site location called Long's Field. 
NEAR-SURFACE MEASUREMENTS IN EXPLORATION GEOPHYSICS

A standard reflection processing flow was undertaken to develop a $3 \mathrm{D}$ volume stack. Due to a complex geology and resulting wavefield, reflections were difficult to separate from other seismic wave modes. We therefore carried out a $2 \mathrm{D}$ and $3 \mathrm{D}$ refraction tomography analysis using two separate methods to characterize the subsurface and map the boundary between the upper sediments and geothermally altered quartz monzonite. Our 2D and 3D refraction tomography results were based upon the commercial refraction tomography softwares RayFract (Intelligent Resources) and Seismic Studio $\left(\right.$ Sigma $\left.^{3}\right)$, respectively. We used model grid cell resolutions of $0.5 \mathrm{~m}$ for the $2 \mathrm{D}$ tomography and $2 \mathrm{~m}$ for the $3 \mathrm{D}$ tomography. For this reason the $3 \mathrm{D}$ refraction results show a significantly smoother representation of the subsurface than the $2 \mathrm{D}$ refraction results.

\section{Results and discussion}

Figure 4 shows the interpretation of a dc resistivity profile whose location is shown in Figure 3. The calculated resistivity values for the section are relatively low, indicating an ab-

\begin{tabular}{|l|l|}
\hline Seismograph & 192-channel geometrics geode \\
\hline Vertical geophones & $40 \mathrm{~Hz}$ \\
\hline Source & $6000-\mathrm{lb}$ industrial vehicles T-15000 \\
\hline Sweep & 12 -s linear $30-300 \mathrm{~Hz}$ \\
\hline Shot spacing & $10 \mathrm{~m}$ inline $(\mathrm{S}-\mathrm{N}) \times 20 \mathrm{~m}$ crossline $(\mathrm{E}-\mathrm{W})$ \\
\hline Receiver spacing & $5 \mathrm{~m}$ inline $(\mathrm{S}-\mathrm{N}) \times 20 \mathrm{~m}$ crossline $(\mathrm{E}-\mathrm{W})$ \\
\hline Sample rate & $1 \mathrm{~ms}$ \\
\hline
\end{tabular}

Table 1. Seismic acquisition parameters.

sence of competent bedrock and instead the presence of clays and severely altered bedrock. Typical resistivity values for altered, saturated, and fractured quartz monzonite that may be further altered to kaolinite ranging from 100 to $2000 \mathrm{ohm}$ $\mathrm{m}$, while competent quartz monzonite ranges from 2000 to $10,000 \mathrm{ohm}-\mathrm{m}$. Abrupt lateral contrasts in resistivity suggest offset stratigraphy that we interpret as near-vertical faults. Figure 4 also shows one of the shot gathers used to create the $2 \mathrm{D}$ velocity tomogram. We interpret two primary re-

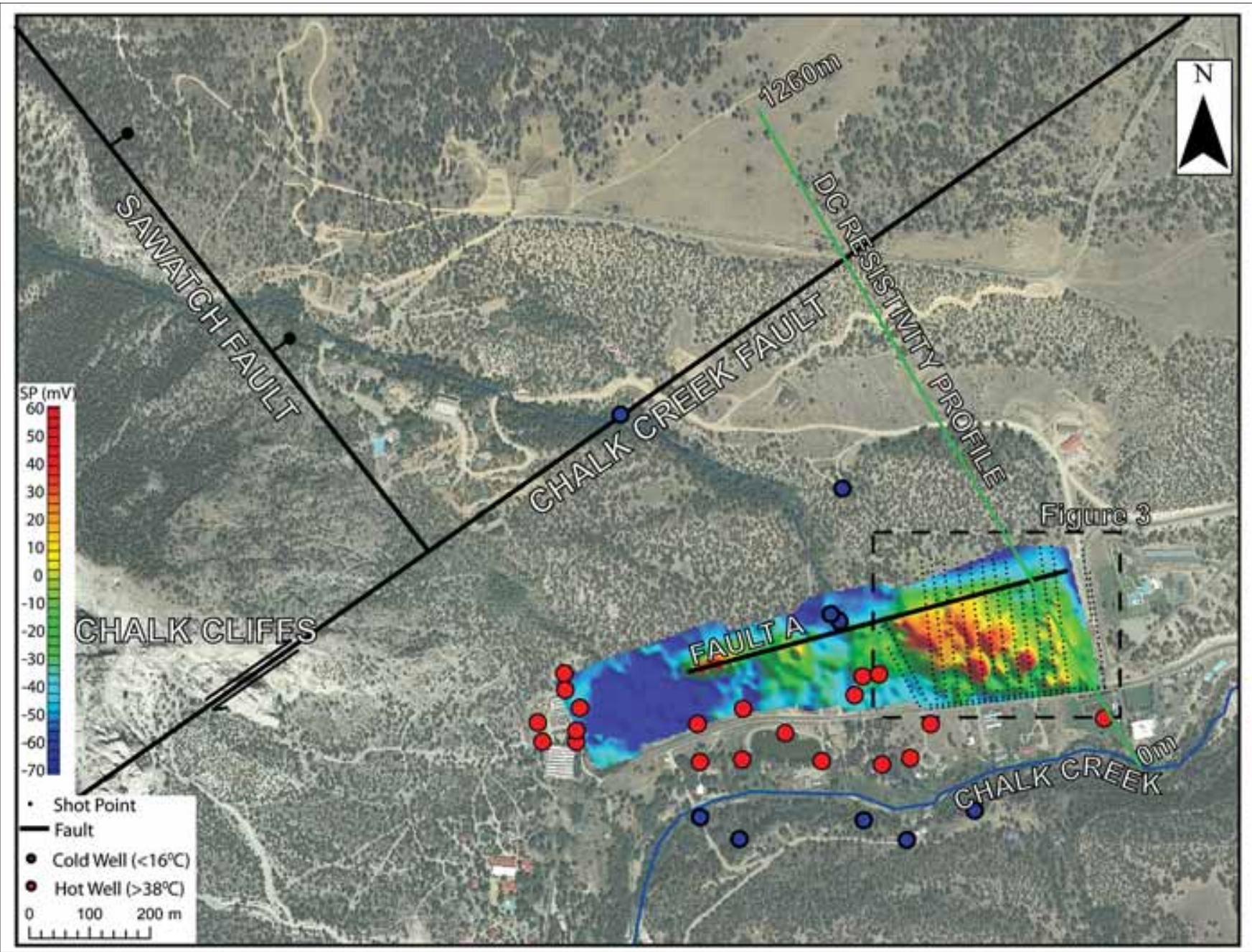

Figure 2. Major fault systems and Long's Field located at the northwest corner of Mount Princeton Hot Springs Resort where the 3D seismic, self-potential, and dc resistivity surveys were conducted. The rainbow colors represent self-potential anomalies in $m V$ with high (red) values indicating upwelling ground water and low values (blue) representing downwelling groundwater. The self-potential anomaly data overlaid with the $3 D$ seismic survey shot points is shown in more detail in Figure 3. 


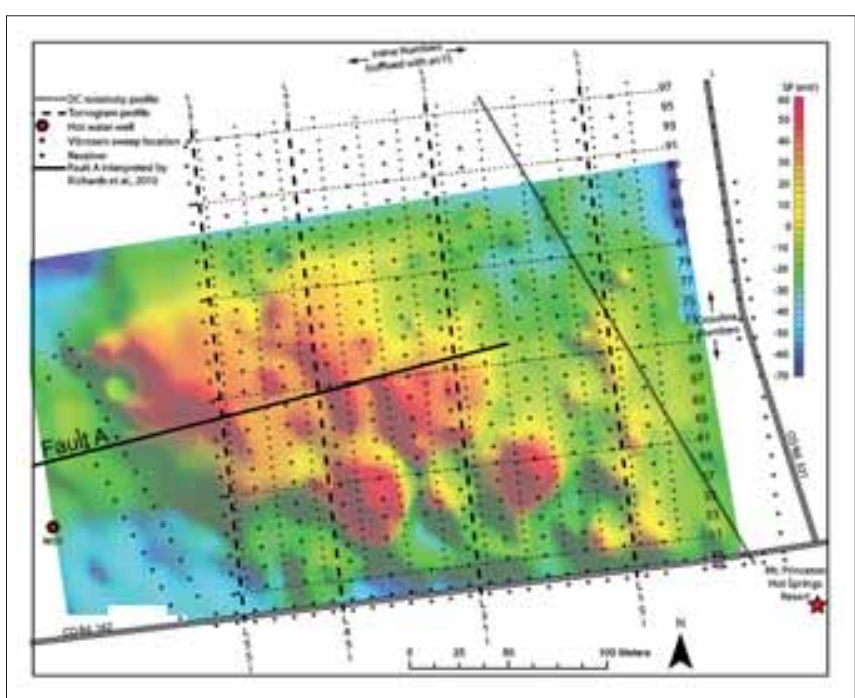

Figure 3. Long's Field at the northwest corner of Mount Princeton Hot Springs Resort where the 3D seismic, self-potential, and $d c$ resistivity surveys were conducted. The rainbow colors represent selfpotential anomalies in $\mathrm{mV}$ with high and low values representing upwelling and downwelling groundwater, respectively. The selfpotential anomaly data are overlaid with the $3 D$ survey grid that shows the nomenclature used for inline and crossline receiver and shot stations and the lines along which velocity tomograms were modeled (dashed lines). The map also shows a $2 D$ dc resistivity profile which traversed in a north-northwest direction across the eastern portions of the field. Fault $A$ is shown to strike east-west across the field, based upon work by Richards et al.

fractions on this shot gather that are generally present on all shot gathers. This shot gather highlights the variability of the deep refraction and shows a 7-ms step along the interpreted bedrock surface near station 91. Linear moveout analyses were performed on the two dominant refractions observed in all 3D shot gathers. This linear moveout analysis found the velocity for the first refraction to be $1750-2100 \mathrm{~m} / \mathrm{s}$ (stations 71 to 85 in shot gathers) while the second refraction was found to be $3100-3300 \mathrm{~m} / \mathrm{s}$ (stations 86 to 98 in shot gathers). We interpret the first refraction as the interface that separates unsaturated and saturated sediments. Water-table information from local wells supports this interpretation. We interpret the $-3200 \mathrm{~m} / \mathrm{s}$ refractor as the bedrock surface; this is supported by a previous deep reflection seismic survey that shows the basement reflector shallowing to similar depths near our site (Blum et al., 2009). In addition, vertical seismic profiling of wells in the valley showed similar bedrock depths and velocities. The relatively low velocity of $-3200 \mathrm{~m} / \mathrm{s}$ for what we expect to be quartz monzonite with velocities in the range of $5000 \mathrm{~m} / \mathrm{s}$ suggest that the bedrock is severely altered and fractured. This low velocity in conjunction with the previously discussed low resistivities $(<100 \mathrm{ohm}-\mathrm{m})$ provides further evidence for severe fracturing and possible alteration to kaolinite as observed on the exposed Chalk Cliffs $800 \mathrm{~m}$ west of Long's Field.

Figures 4 and 5 show velocity profiles from 2D refraction modeling and each tomogram is plotted with the corresponding self-potential data. Our interpretations are based

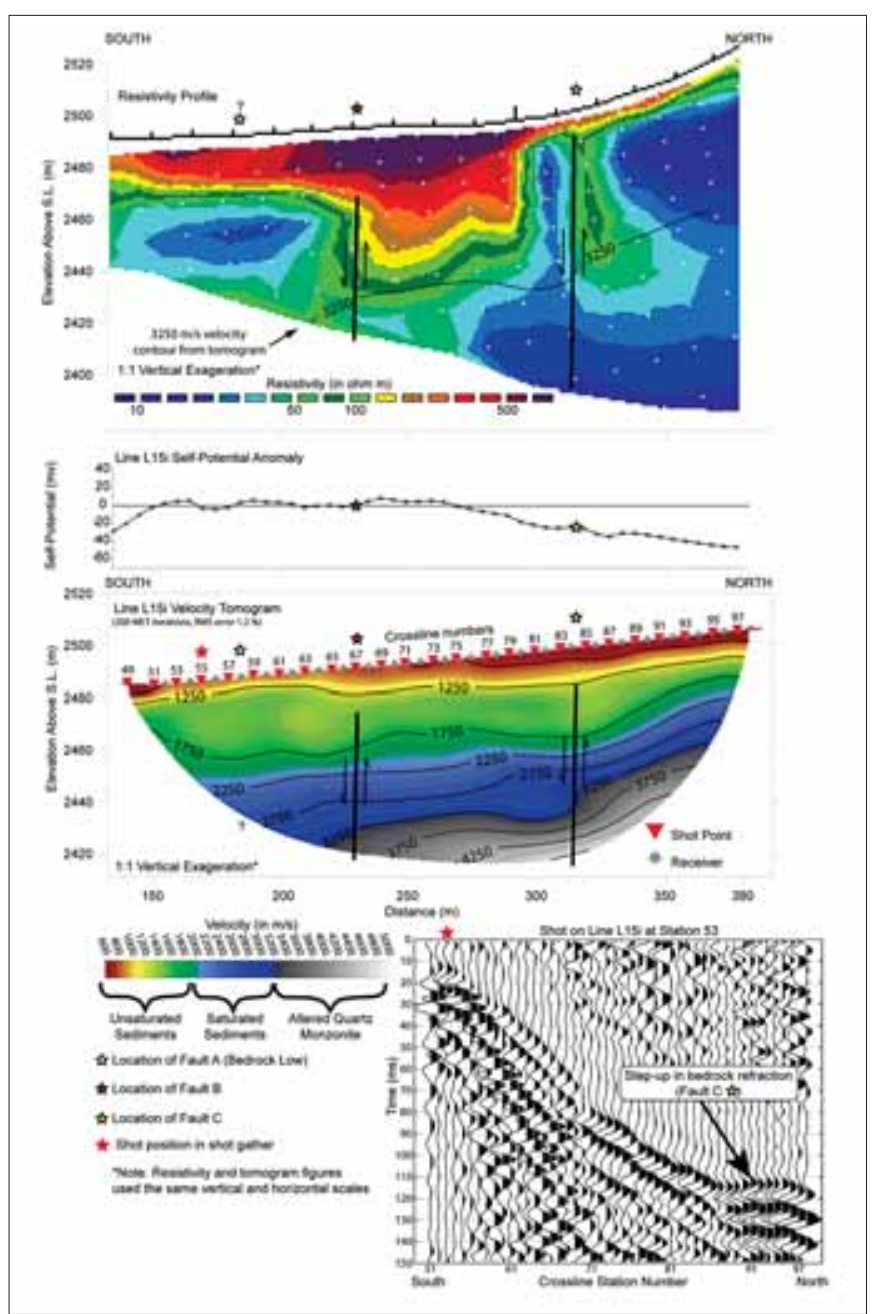

Figure 4. The top panel shows the dc resistivity inversion result (using commercial code 2DRESINV) for the do resistivity profile shown in Figures 2 and 3. The resistivity data were acquired using a Wenner array with 20-m electrode spacing. The remaining two panels show the self-potential and $2 D$ refraction tomography results for $215 i$ (Figure 3). We interpret the tomogram to represent unsaturated sediments, saturated sediments, and altered quartz monzonite. We interpret two faults (fault $B$ and fault $C$ ) to coincide with steps in bedrock at crossline stations 67 and 84, respectively. The interpreted faults correspond with lateral contrasts on the resistivity profile. We also have represented the location of the bedrock low from our $3 D$ refraction modeling results using a white star and we interpret this to coincide with fault $A$ as interpreted by Richards et al.

upon our combined observations on all the processed 2D and 3D seismic and potential-field data. The refraction tomography inherently smoothes the subsurface structure and this is also true of the self-potential and dc resistivity inversions. For these reasons, our interpretations take into account these smoothing affects and faults are interpreted where large lateral gradients appear in the velocity or dc resistivity models. The $2 \mathrm{D}$ velocity tomograms all show the bedrock dipping to the south with average bedrock dips between $4^{\circ}$ and $20^{\circ}$ and localized maximum dips of up to $50^{\circ}$ (e.g., stations 73 and 85 on L31i and station 77 on L15i). The eastern lines L15i and L31i have the highest dip angles. Line L15i shows a $-15 \mathrm{~m}$ southside-down offset in the bedrock at station 84 and a 


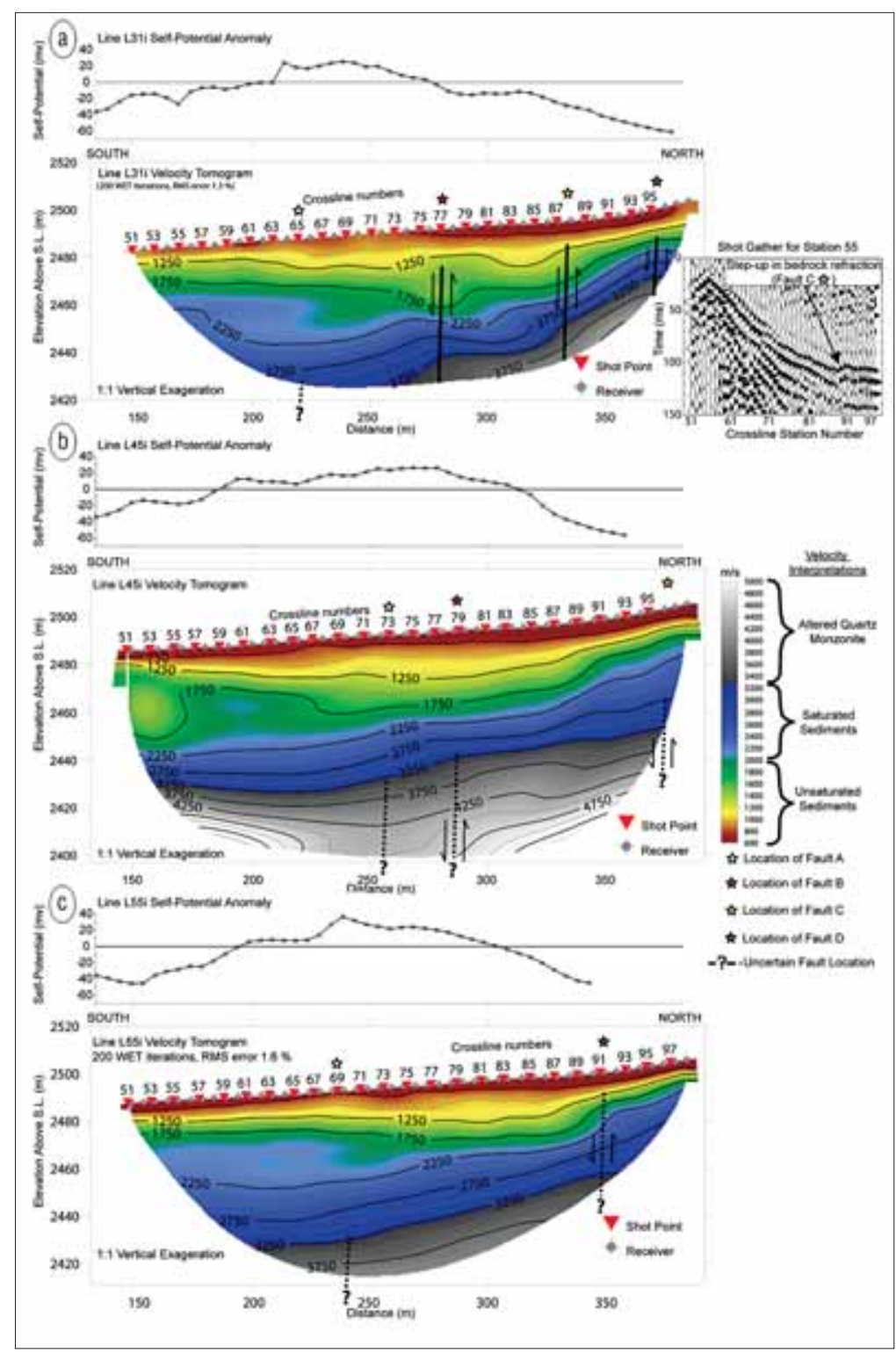

Figure 5. (a), (b), and (c) show the self-potential and 2D refraction tomography results for lines L31i, L45i, and L55i shown in Figure 3. Our interpreted locations of faults $A$ through $D$ are shown on each of the three figures along with a shot gather from station 55 on line L31i. The shot gather shows a step-up in the bedrock refraction at station 91 that is common to many of the shots shooting northward in the eastern half of Long's Field.

further southside-down offset at station 67 . These two southside-down bedrock offsets in line L15i correspond with two steeply dipping low-resistivity anomalies observed in the results of a $2 \mathrm{D}$ dc resistivity profile that was acquired diagonally across L15i (Figures 3 and 4). These anomalies are indicative of faulting and their low resistivities may be due to the presence of hot water and increased alteration. The superposition of resistivity and seismic anomalies provides strong evidence for two faults that we term faults B and C. We identify three southside-down bedrock offsets on Line L31i (Figure 5) at stations 95,88 , and 77 . Offsets of $-10 \mathrm{~m}$ at stations 88 and 77 are similar in throw to the offsets at stations 88 and 67 on line L15i and we interpret these steps in bedrock as con- tinuations of faults B and C. The L45i and L55i velocity tomograms (Figure 5) that lie further to the west do not exhibit similar bedrock offsets to lines L15i and L31i; however, there are more subtle southside-down offsets at the mid-to-northern portions of these lines that may represent westward continuations of faults (Figure 5).

The 3D tomography and self-potential maps are presented, respectively, in Figures 6a and 6b. Figure 6 a shows a $20-50^{\circ}$ south-dipping bedrock surface at the northern section of the field and both figures show evidence for anomalies trending northwestsoutheast. These trends are more subtle in the 3D tomography results than the self-potential results; however, a combined interpretation of these maps with our 2D interpretations (shown in Figures 4 and 5) suggests that faults $B$ and $C$ and the less well constrained fault $\mathrm{D}$ likely follow a similar strike direction. Fault $\mathrm{C}$ lies along the northern margin of the self-potential anomaly and may therefore be a northern-bounding fault for upwelling hot water. This interpretation is consistent with well temperature data and fault $\mathrm{A}$ interpreted by Richards et al., who showed that fault A lies parallel to a boundary between hot water wells to the south and cold water wells to the north.

The bedrock contours, generally east-west trending, in Figure 6a may represent glacial erosion within Chalk Creek Valley with fault A coincident with a low in the bedrock surface. Faults $\mathrm{B}, \mathrm{C}$, and $\mathrm{D}$ all offset the bedrock surface in a northwest-southeast direction and appear to follow similar trends in the individual smaller scale self-potential anomalies of Figure 6b. These faults have negative self-potential anomalies (representative of downwelling water) and may be conduits for downwelling cold water and boundaries for upwelling hot water along the positive self-potential anomaly. The west-east zone of larger scale positive self-potential anomalies (see Figure 2), align in the same general direction of the bedrock topography interpreted from seismic refraction data (Figure 6). The axial bedrock low is also coincident with fault $A$ that aligns with the larger-scale positive selfpotential anomaly to the west (Figure 3) and may be related to an area of structural weakness in the bedrock. It is possible that the bedrock axial low is an apparent low caused by upwelling hot water degrading the quartz monzonite and slowing down the velocity. It is inconsequential as to whether the bedrock low is real or apparent because a bedrock low or velocity slowdown could both be interpreted to represent an area of structural weakness and a source of upwelling hot water.

\section{Conclusions}

Our investigations have shown a correlation between the seismic, self-potential, and dc resistivity data and how these 


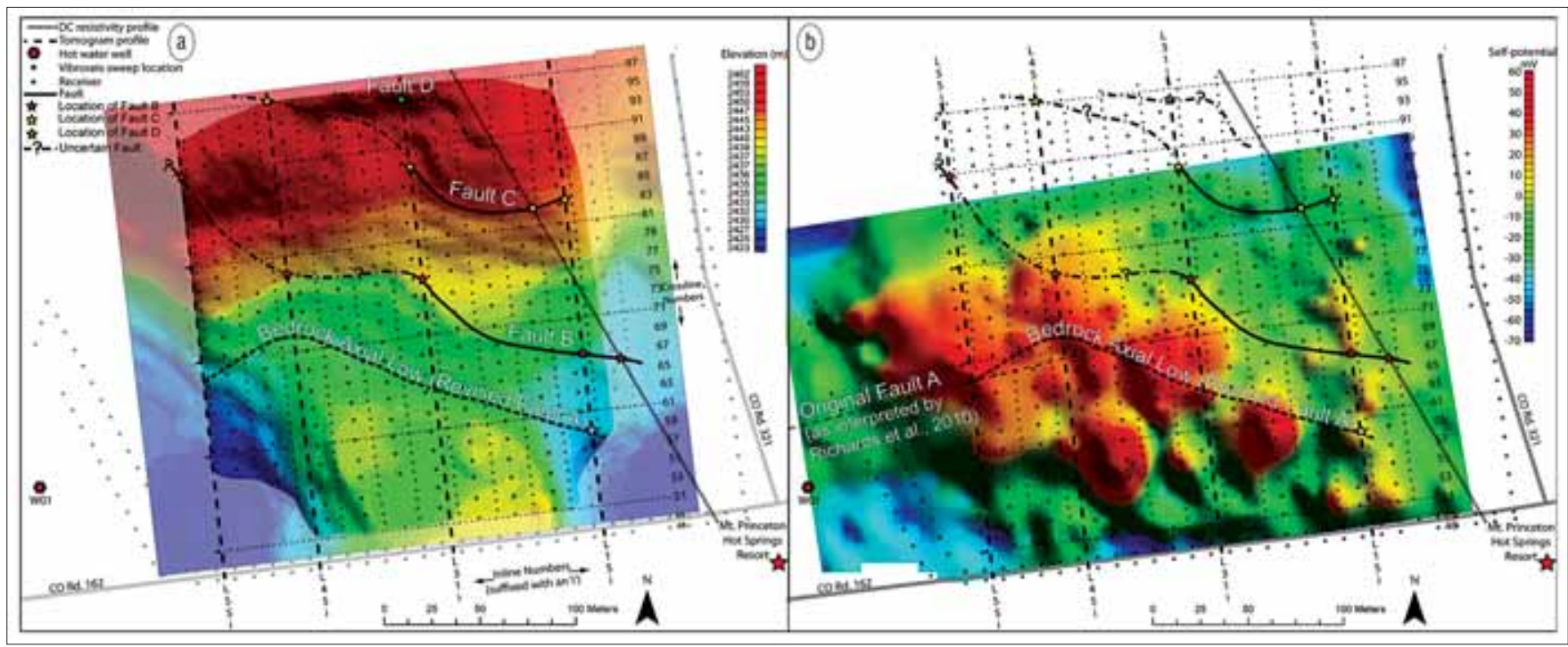

Figure 6. (a) and (b) Interpretations superimposed on the 3D refraction tomography and self-potential results, respectively. (a) The elevation above sea level for the $3250 \mathrm{~m} / \mathrm{s}$ velocity isosurface. The $3250 \mathrm{~m} / \mathrm{s}$ velocity isosurface is interpreted to represent the top of the altered quartz monzonite where high elevation is represented by red and low elevation by blue. The bedrock surface elevation is overlaid with the 3D seismic survey grid that shows the $2 D$ tomogram and resistivity profile locations. The subdued colors bordering the $3 D$ refraction results represent areas of low ray coverage for which the calculated velocities are not well constrained.

combined data sets can be successfully used to characterize the near surface of a geothermal system. We have presented evidence for three faults and a bedrock low axis by jointly interpreting seismic, self-potential, and resistivity data. Our interpretations indicate that the positive east-west self-potential anomaly follows a low axial surface in the bedrock that may alternatively be a low-velocity zone representative of quartz monzonite that is severely altered by upwelling hot water. Our interpretations also suggest that faults B, C, and $\mathrm{D}$ may be bounding faults for the northern edge of the self-potential anomaly and are conduits for downwelling cold water. The strike directions of faults B, C, and D follow a northwest-to-southeast trend that aligns with a dilatant stress field radiating from the intersection of the Sawatch and Chalk Creek faults. The upwelling hot water events observed by self-potential methods appear to follow a bedrock low/ weakness whose strike direction passes through the Mount Princeton Hot Springs resort. This bedrock low/weakness is likely responsible for the hot water springs naturally upwelling in the area, as previously stated by Richards et al. We also conclude that the staggered northwest-southeast striking faults and low bedrock velocities all suggest the quartz monzonite is both significantly fractured and geothermally altered. FEE

\section{References}

Blum, T., K. van Wijk, M. Batzle, R. Krahenbuhl, A. Revil, and R. Reynolds, 2009, Characterization of a geothermal system in the Upper Arkansas Valley, CO: 79th Annual International Meeting, SEG, Expanded Abstracts, 1289-1293.

Fairley, J. and J. Hinds, 2004, Rapid transport pathways for geothermal fluids in an active Great Basin fault zone: Geology, 32, no. 9, 825-828, doi:10.1130/G20617.1.
Richards, K., A. Revil, A. Jardani, F. Henderson, M. Batzle, and A. Haas, 2010, Pattern of shallow ground water flow at Mount Princeton Hot Springs, Colorado, using geoelectrical methods: Journal of Volcanology and Geothermal Research, 198, no. 1-2, 217-232, doi:10.1016/j.jvolgeores.2010.09.001.

Roberts, G. P., 1996, Variation in fault-slip directions along active and segmented normal fault systems: Journal of Structural Geology, 18, no. 6, 835-845, doi:10.1016/S0191-8141(96)80016-2.

Acknowledgments: Funding for this work was provided by DOE Award G018195. Additional funding for the vibroseis was provided by the NSF. We thank the local community and land owners for allowing access to their properties and particularly Bill Moore and Stephen Long. We also thank Chaffee County, the SEG Foundation, ION Geophysical, field camp students, and other local stakeholders for their support. The seismic, dc electrical resistivity, and self-potential data were acquired from 2008 to 2010 as part of the spring geophysical field camp attended by students from the Colorado School of Mines, Boise State University, and Imperial College London. Specific individuals who contributed to this work include Mike Batzle, Kyle Richards, Abderrahim Jardani, Fred Henderson, John Bradford, Thomas Blum, and Dylan Mikesell.

Corresponding author: andrewlamb@u.boisestate.edu 